\title{
The BH3 domain of BAD fused to the Antennapedia peptide induces apoptosis via its alpha helical structure and independent of $\mathrm{Bcl}-2$
}

\author{
AD Schimmer ${ }^{1}$, DW Hedley ${ }^{1}$, S Chow ${ }^{1}$, N-A Pham ${ }^{1}$, \\ A Chakrabartty ${ }^{1}$, D Bouchard ${ }^{1,2}$, TW Mak ${ }^{1,2}$, MR Trus ${ }^{1}$ \\ and MD Minden ${ }^{1}$ \\ ${ }^{1}$ Princess Margaret Hospital, University Health Network, Toronto, Ontario, \\ Canada \\ 2 Amgen Institute, Toronto, ON, Canada \\ * Corresponding author: MD Minden, Princess Margaret Hospital, Room 9-111, \\ 610 University Ave, Toronto, ON M5G2M9, Canada, Tel: 416-946-2000; \\ Fax: 416-946-2065; E-mail: minden@uhnres.utoronto.ca
}

Received 8.11.00; revised 30.1.01; accepted 18.2.01

Edited by CJ Thiele

\begin{abstract}
Since the over-expression of $\mathrm{Bcl}-2$ is a common cause of multi-drug resistance, cytotoxic peptides that overcome the effects of Bcl-2 may be clinically useful. We harnessed the death-promoting alpha helical properties of the $\mathrm{BH} 3$ domain of BAD by fusing it to the Antennapedia (ANT) domain, which allows for cell entry (ANTBH3BAD). Treatment of 32D cells with the ANTBH3BAD peptide results in a $99 \%$ inhibition of colony formation. No significant toxicity is observed after treatment with ANT or BH3BAD alone. A mutant fusion peptide unable to bind $B c 1-2$ induces cell death as effectively as the wild-type ANTBH3BAD. Furthermore, 32D cells over-expressing Bcl-2 show no resistance to the ANTBH3BAD peptide. Therefore, the toxicity of the peptide was independent of the Bcl-2 pathway. We demonstrate that the toxicity of the peptide is due to its alpha helicity that disrupts mitochondrial function. Since this peptide overcomes major forms of drug resistance, it may be therapeutically useful if appropriately targeted to malignant cells. Cell Death and Differentiation (2001) 8, 725-733.
\end{abstract}

Keywords: apoptosis; alpha helix; mitochondria; Bcl-2; caspases

Abbreviations: ANT, Antennapedia; $\mathrm{BH} 3 \mathrm{BAD}, \mathrm{BH} 3$ domain of $\mathrm{BAD}$; $\mathrm{CD}$, circular dichroism; $\Delta \Psi_{\mathrm{M}}$, mitochondrial membrane potential; $\mathrm{ROI}$, reactive oxygen intermediates

\section{Introduction}

Since the over-expression of $\mathrm{Bcl}-2$ is a common mechanism by which malignant cells become resistant to multiple chemotherapeutic agents, ${ }^{1-5}$ cytotoxic peptides that overcome $\mathrm{Bcl}-2$-mediated drug resistance may be useful in the treatment of malignant disease. One example is the alpha helical $\mathrm{BH} 3$ domain of BAD that binds and inhibits $\mathrm{Bcl}-2$ and $\mathrm{Bcl}-\mathrm{xL} .{ }^{6,7}$ Wang et al. ${ }^{8}$ created a cell-permeable version of the peptide by fusing it to cpm, a decanoic fatty acid internalization sequence. This fusion peptide induced rapid cell death and apoptosis. However, its cytotoxicity was significantly impaired by the over-expression of Bcl-xL, which could limit the usefulness of this compound in treating malignancies with increased levels of $\mathrm{Bcl}-2$ and $\mathrm{Bcl}-\mathrm{xL}$. Therefore, enhancing the ability of the $\mathrm{BH} 3$ domain of $\mathrm{BAD}$ to kill cells over-expressing these survival factors might be therapeutically useful. One strategy to enhance its toxicity is to capitalize on the inherent alpha helical shape of the peptide, since some amphipathic alpha helices are potent naturally occurring antibiotics. These compounds disrupt negatively charged bacterial membranes, but are not toxic to the mammalian cells, because their membranes are neutrally charged and stabilized by cholesterol. ${ }^{9-11}$ When internalized into mammalian cells, however, the alpha helical peptide $(\mathrm{KLALAK})_{2}$ induced cell death and apoptosis by disrupting the negatively charged mitochondria. ${ }^{12}$

Here, we have harnessed the alpha helical properties of the $\mathrm{BH} 3$ domain of BAD by fusing it to the Antennapedia internalization sequence. We have created a 37 amino acid fusion peptide corresponding to the 21 amino acids of the human $\mathrm{BH} 3$ domain of $\mathrm{BAD}$ fused to the $\mathrm{C}$-terminus of the 16 amino acids of the ANT peptide (ANTBH3BAD). ANT is an internalization sequence that successfully translocates across a variety of cell membranes with high efficiency and low toxicity. ${ }^{13-15}$ We report that the ANTBH3BAD fusion peptide induces rapid cell death and apoptosis. Its alpha helical secondary structure disrupts mitochondrial function and allows the peptide to overcome caspase inhibitors and $\mathrm{Bcl}-2$ over-expression.

\section{Results}

\section{Bcl-2 binds ANTBH3BAD and BH3BAD, but not ANT}

To demonstrate that ANTBH3BAD binds $\mathrm{Bcl}-2$, the interaction between $\mathrm{Bcl}-2$ and the peptides was analyzed with real time surface plasmon resonance detection. ANTBH3BAD, BH3BAD and ANT peptides and BSA were coupled to a biosensor chip through their amine groups. GST-Bcl-2 was injected at increasing concentrations onto the sensor chip and binding to the peptides above the BSA control was measured. GST-Bcl-2 bound avidly to ANTBH3BAD and BH3BAD in a dose-dependent manner and did not bind significantly to ANT (Figure 1). Bcl-2 remained tightly bound to the peptides with minimal dissociation. GST alone did not bind to the peptides. 


\section{Internalization of the peptides}

ANT is an internalization sequence that facilitates the transport of peptides across cell membranes with high efficiency. To study the internalization and localization of our peptides, 32D cells were treated with biotinylated versions of ANT and ANTBH3BAD. In a representative experiment, 89 and $100 \%$ of $32 \mathrm{D}$ cells treated with biotinyated ANT or ANTBH3BAD, respectively, internalized the peptides as measured by flow cytometry. The peptides were distributed diffusely throughout the nucleus and cytoplasm as determined by confocal fluorescent microscopy (Figure 2).

\section{ANTBH3BAD induces a rapid cell death}

To assess the impact of the peptides on cell viability, HeLa cells were treated with $50 \mu \mathrm{M}$ of ANT, BH3BAD or ANTBH3BAD for $3 \mathrm{~h}$. Cells treated with ANTBH3BAD displayed morphologic evidence of cell death characterized by cell shrinkage, membrane blebbing, and detachment from the tissue culture plate. In contrast, no significant morpholo-
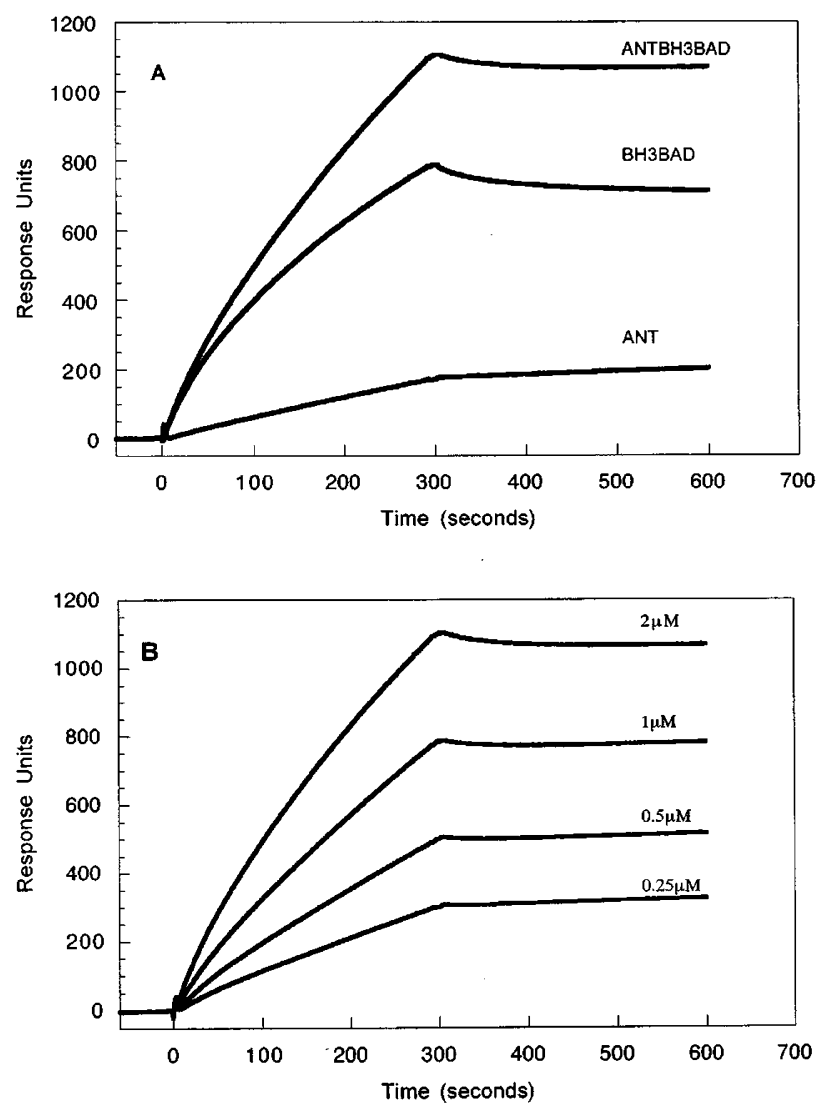

Figure 1 Real time surface plasmon resonance. BH3BAD, ANT, ANTBH3BAD and BSA were coupled to a CM5 BIAcore sensor chip. GST-Bcl-2 was injected onto the chip at increasing concentrations. The sensor surface was regenerated with $1 \mathrm{M} \mathrm{NaCl}$ and $50 \mathrm{mM} \mathrm{NaOH}$ between each injection. Binding to the peptides above the BSA control was measured as an increase in Response Units above the BSA control. A representative sensogram after the injection of GST-Bcl-2 $(2 \mu \mathrm{M})$ is shown (A). A dose response curve for the binding of GST-Bcl-2 to ANTBH3BAD is presented (B) gical changes were seen after treatment with $50 \mu \mathrm{M}$ ANT or BH3BAD (Figure 3).

To quantitate the effects of the peptides on cell survival, HeLa, 32D and yeast cells were treated with the peptides at a final concentration of $50 \mu \mathrm{M}$ and cell survival was measured by a colony formation assay. Dramatic decreases in cell survival were seen in all three cell types after treatment with ANTBH3BAD. No significant toxicity was observed in cells treated with ANT or BH3BAD alone (Figure 4). Therefore, ANTBH3BAD induces cell death, but the toxicity is not related to the ANT domain. The BH3BAD peptide alone is not toxic because it is not internalized.

Dose response curves for ANTBH3BAD-induced cell death were constructed. 32D cells were treated with increasing concentrations of ANTBH3BAD peptide for $3 \mathrm{~h}$ and cell survival was measured in a colony formation

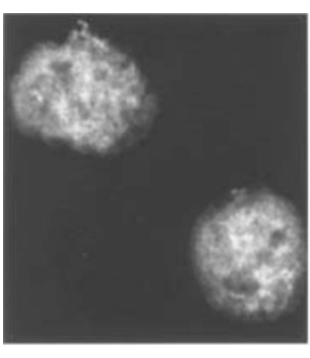

ANTBH3BAD

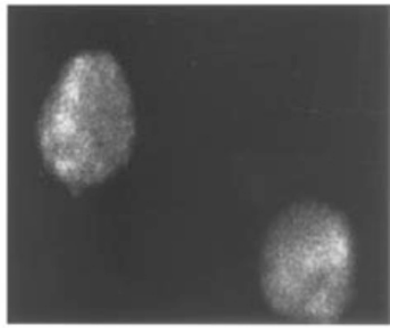

ANT
Figure 2 Internalization of the peptides. Biotinylated versions of ANT and ANTBH3BAD were obtained. $32 \mathrm{D}$ cells $\left(1 \times 10^{6}\right.$ cells $)$ were treated with the peptides at a final concentration of $50 \mu \mathrm{M}$ for $20 \mathrm{~min}$. The cells were washed, fixed in $4 \%$ paraformaldehyde, permeabilized with $1 \%$ Triton X-100 and probed with Streptavidin-FITC to detect the biotinylated peptides. Cells were viewed under a fluorescent confocal microscope to determine the distribution of the peptide

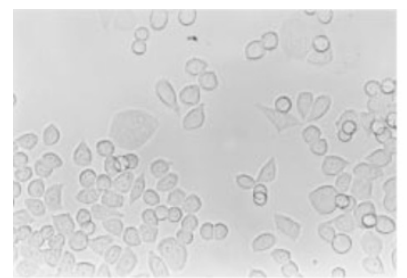

ANT

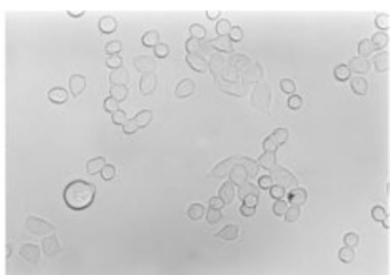

$\mathrm{BH} 3 \mathrm{BAD}$

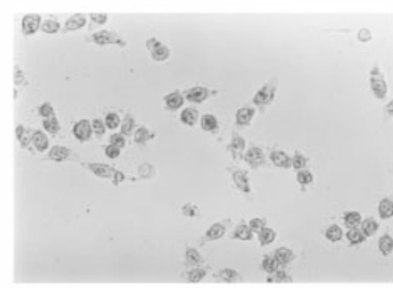

ANTBH3BAD

Figure 3 Morphologic evidence of cell death. HeLa cells $\left(1 \times 10^{5}\right.$ cells) were seeded into 12 -well plates in DMEM H21+10\% fetal calf serum. Twenty-four hours later, BH3BAD, ANT and ANTBH3BAD were added to the cells in SFDMEM H21 at a final concentration of $50 \mu \mathrm{M}$. Three hours after incubation, morphologic evidence of cell death was observed among the cells treated with ANTBH3BAD. Cells treated with ANT or BH3BAD showed no evidence of toxicity 


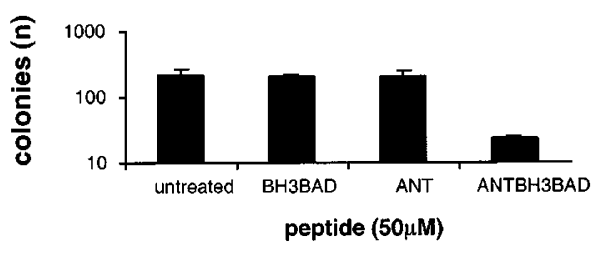

HeLa

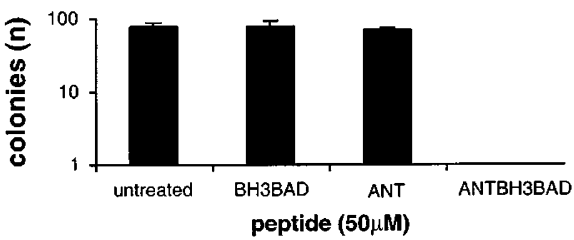

$32 \mathrm{D}$

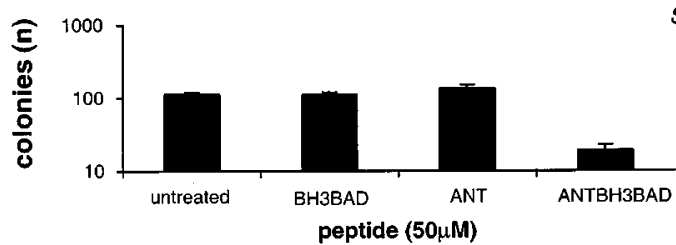

S. cerevisiae

Figure 4 ANTBH3BAD induces cell death. HeLa cells, 32D cells and $S$. cerevisiae were treated with BH3BAD, ANT, or ANTBH3BAD at a final concentration of $50 \mu \mathrm{M}$ for $3 \mathrm{~h}$. After the incubation, equal volumes of cells were plated in a colony formation assay as described in Materials and Methods. The number of colonies formed was counted

assay. As the peptide concentration increased, there was a corresponding decrease in cell survival observed (Figure 5). The dose response curve was steep, as minimal toxicity was observed below a peptide concentration of $10 \mu \mathrm{M}$ and nearly complete growth inhibition was seen at a concentration of $50 \mu \mathrm{M}$.

\section{ANTBH3BAD induces apoptosis}

Next, we determined whether the cell death induced by ANTBH3BAD occurred via apoptosis. 32D cells were treated with the peptides for 30 min and stained with FITC labeled anti-Annexin $\mathrm{V}$ and $\mathrm{PI}$. The percentage of apoptotic cells was determined by flow cytometric analysis. After treatment with ANTBH3BAD $97 \pm 1 \%$, of cells were apoptotic based on Annexin $V$ staining. In contrast, only $15 \pm 2 \%$ of cells treated with ANT and $13 \pm 2 \%$ of cells treated with BH3BAD were apoptotic by Annexin $\mathrm{V}$ staining.

\section{ANTBH3BAD induces cell death independent of $\mathrm{Bcl}-2$}

We studied the effects of $\mathrm{Bcl}-2$ over-expression on the toxicity of ANTBH3BAD. 32D cells with and without over-expression of murine Bcl-2 $\left(5 \times 10^{5}\right.$ cells) were treated with ANTBH3BAD and cell viability was measured by trypan blue extrusion. Over-expression of $\mathrm{Bcl}-2$ did not abrogate the toxicity of our peptide (Figure 6). In contrast, 32D cells over-expressing Bcl2 were protected from IL-3 withdrawal, indicating that $\mathrm{Bcl}-2$ can protect this cell line from other apoptotic stimuli.

To confirm the lack of impact of Bcl-2 on the toxicity of ANTBH3BAD, a mutant fusion peptide was obtained in which residues $\mathrm{L} 114$ and $\mathrm{D} 119$ in the $\mathrm{BH} 3$ domain of BAD were substituted with $\mathrm{A} 114$ and R119. In a BIAcore binding assay, GST-Bcl-2 did not bind to this mutant peptide. Although incapable of binding Bcl-2, the mutant peptide was as toxic as the wild type indicating that the toxicity of ANTBH3BAD is independent of the Bcl-2 pathway.

\section{Toxicity of the fusion peptide is due to its alpha helical shape}

Certain alpha helical peptides are potent antimicrobial agents that induce cell death by disrupting the negatively charged bacterial cell membrane. ${ }^{9,10}$ When internalized into eukaryotic

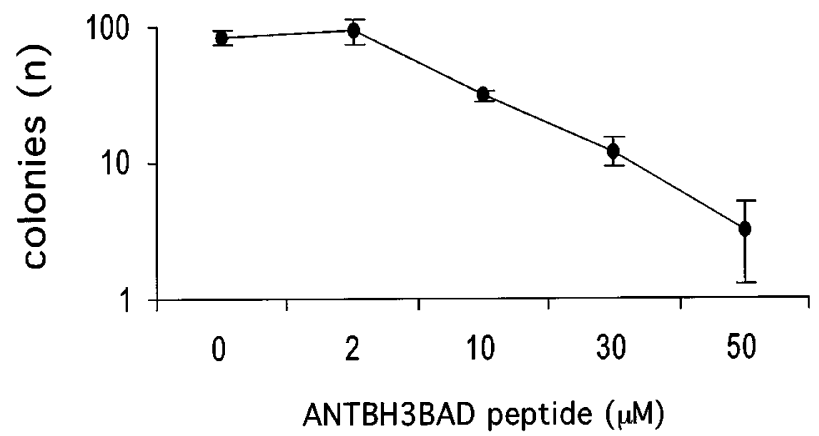

Figure 5 Dose response curve. A dose response curve for ANTBH3BADinduced cell death was constructed. 32D cells were incubated with increasing concentrations of ANTBH3BAD for $3 \mathrm{~h}$. After incubation, equal volumes of cells were plated in a colony formation assay as described in Materials and Methods. One week later, the number of colonies formed was counted

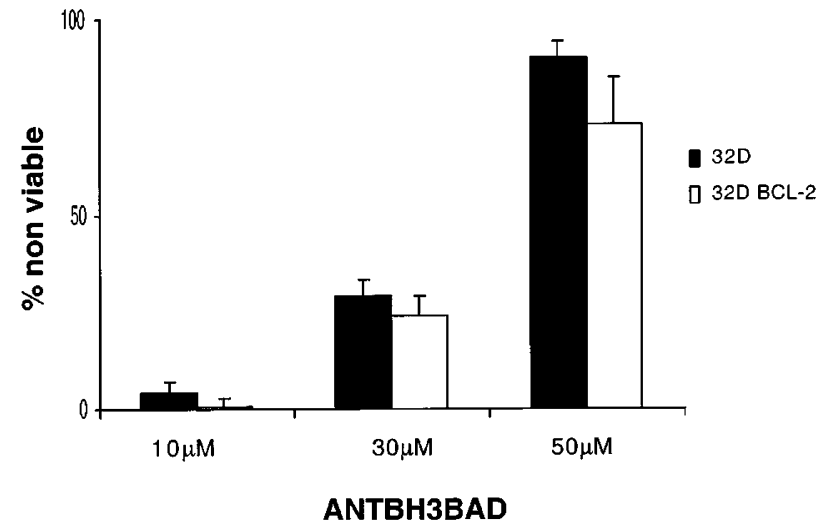

Figure $6 \mathrm{Bcl}-2$ does not abrogate the toxicity of the fusion peptide. 32D cells and $32 \mathrm{D}$ cells over-expressing $\mathrm{Bcl}-2$ were treated with ANTBH3BAD at finalconcentrations of 10,30 and $50 \mu \mathrm{M}$. Six hours after treatment, an equal volume of trypan blue was added. The percentage of cells staining positive for trypan blue was determined. The results represent the mean of three experiments 
cells, alpha helical peptides induce apoptosis by disrupting the negatively charged mitochondria. ${ }^{12}$ ANTBH3BAD is predicted to have an alpha helical conformation. To evaluate the contribution of the helical shape to its toxicity, we created, a non-helical mutant of ANTBH3BAD by substituting A106, A107, and L114 in BH3BAD with prolines. We tested the impact of this mutation on helical structure by circular dichroism (CD) (Figure 7). In $100 \mathrm{mM}$ phosphate buffer (pH 7), both the wild type and non-helical mutant ANTBH3BAD peptides displayed a CD spectrum consistent with a random coil. However, the wild-type peptide adopted an alpha helical
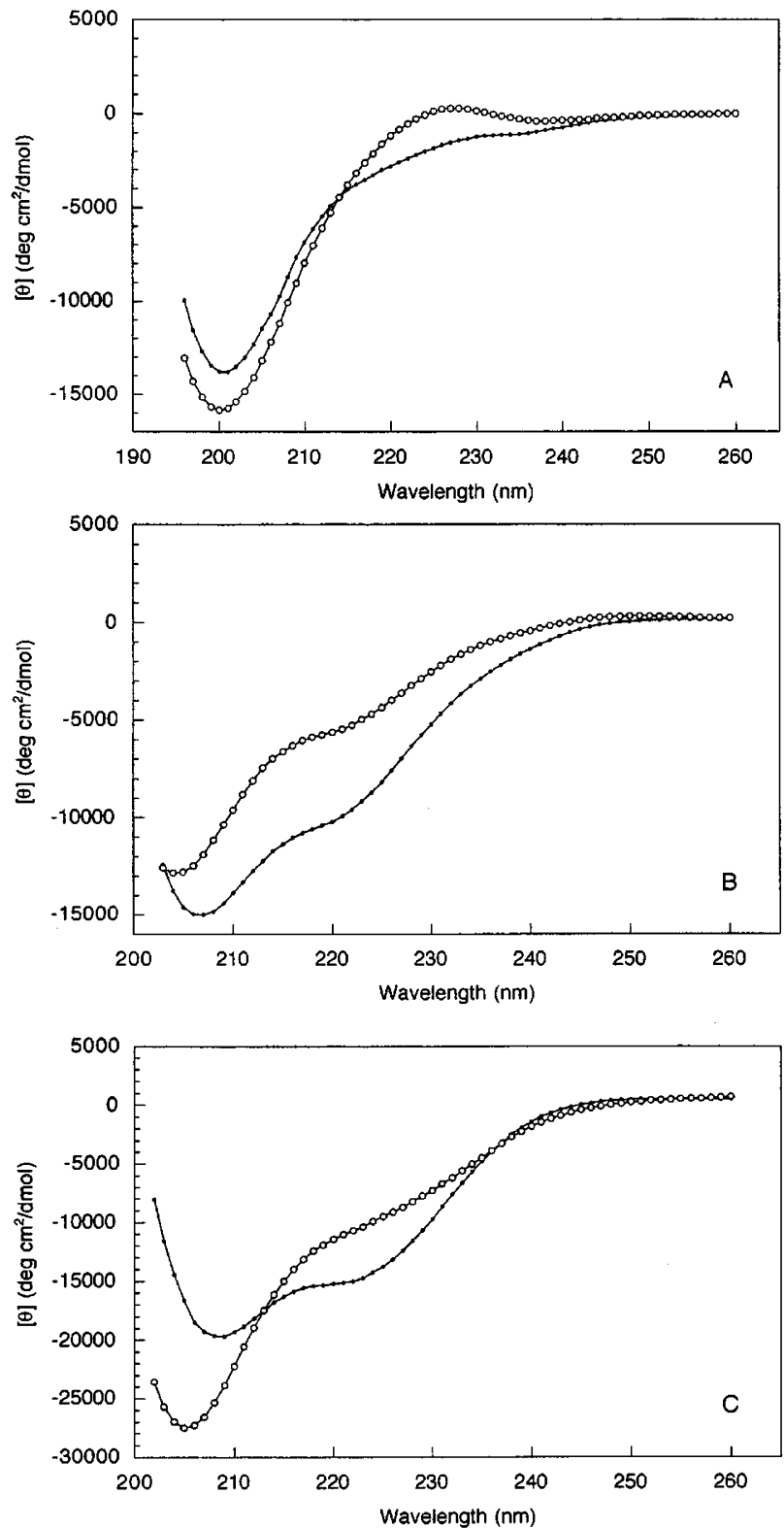

Figure 7 Circular dichoism. The secondary structure of ANTBH3BAD and the non-helical mutant were determined by circular dichroism. The peptides were dissolved in $0.1 \mathrm{M} \mathrm{NaH}_{2} \mathrm{PO}_{4}$ buffer (A), $1 \%$ SDS (B), or $40 \%$ (v/v) TFE (C). CD spectra were recorded at room temperature. Each point represents the averaged ellipticity value recorded over $1 \mathrm{~nm}$ spectral intervals.

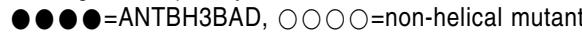

conformation in $1 \%$ SDS and $40 \%(\mathrm{v} / \mathrm{v})$ TFE, but the nonhelical mutant mainly remained as a random coil in these solutions. In addition, the ANT and BH3BAD peptides alone adopted alpha helical secondary structure in these solutions.

A colony formation assay was performed with the nonhelical mutant to determine the contribution of the alpha helicity to the toxicity of ANTBH3BAD (Figure 8). The nonhelical mutant was not toxic to $32 \mathrm{D}$ cells demonstrating that the toxicity of ANTBH3BAD depends on its helical configuration.

\section{ANTBH3BAD disrupts mitochondrial function}

Alpha helical peptides induce swelling of isolated mitochondria. Therefore, to confirm that the cytotoxcity of ANTBH3BAD was related to its helical configuration, we investigated the effects of the peptides on intracellular mitochondrial function. Hallmarks of mitochondrial dysfunction include loss of mitochondrial membrane potential $\left(\Delta \Psi_{\mathrm{M}}\right)$ and increased production of reactive oxygen intermediates (ROI). Changes in $\Delta \Psi_{\mathrm{M}}$ and $\mathrm{ROI}$ production were measured over time by flow cytometry after treating $32 \mathrm{D}$ cells with the peptides. ANTBH3BAD rapidly decreased $\Delta \Psi_{\mathrm{M}}$, whereas no significant change was observed after treatment with ANT or BH3BAD (Figure 9). The non-helical mutant also did not induce loss of $\Delta \Psi_{\mathrm{M}}$. The population with decreased $\Delta \Psi_{\mathrm{M}}$ also showed increased ROI production. The increased ROI and decreased $\Delta \Psi_{\mathrm{M}}$ were not accompanied by significant increases in cytosolic calcium. Therefore, the loss of $\Delta \Psi_{\mathrm{M}}$ is not secondary to large increases in cytosolic calcium from disruption of the endoplasmic reticulum.

To ensure that the toxicity of ANTBH3BAD is due to the alpha helical properties of BH3BAD and not an artifact of the fusion peptide, we investigated the effects of BH3BAD on $\Delta \Psi_{\mathrm{M}}$ in permeablized cells. $32 \mathrm{D}$ cells were suspended in respiratory buffer to mimic the environment of the

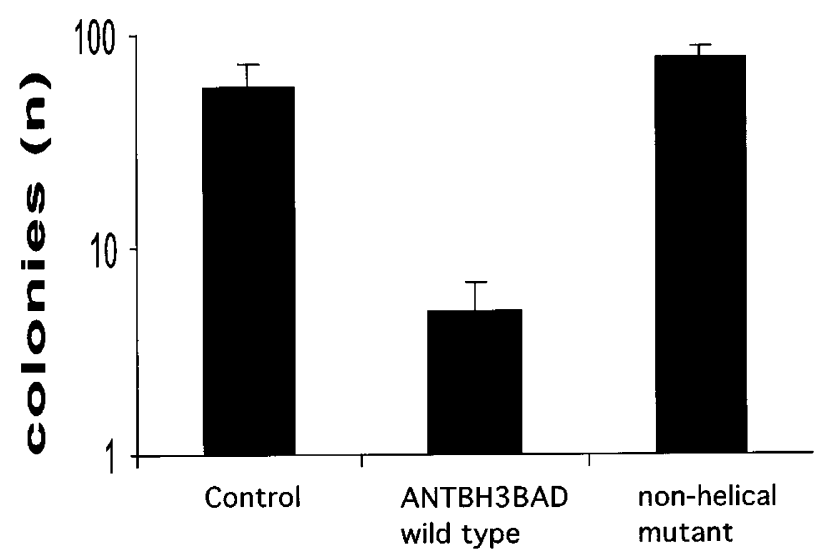

Peptide $(50 \mu \mathrm{m})$

Figure 8 The non-helical mutant is non toxic. 32D cells $\left(5 \times 10^{4}\right.$ cells $)$ were treated with ANTBH3BAD or the non-helical mutant at a final concentration of $50 \mu \mathrm{M}$. After a 3-h incubation, equal volumes of cells were plated into complete medium with $0.85 \%$ methyl cellulose. One week after seeding, the number of colonies formed was counted 
A

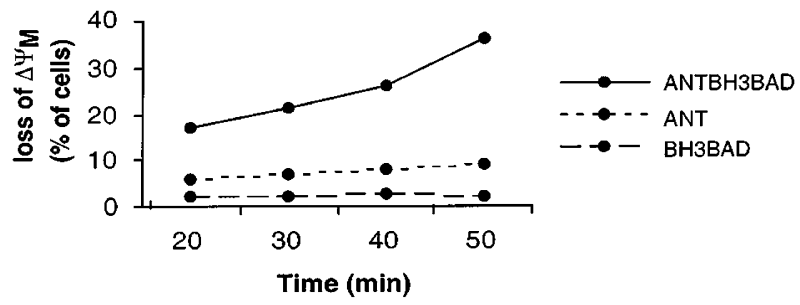

B

untreated

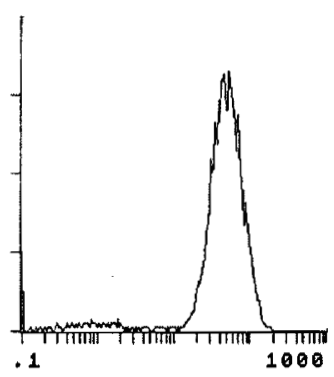

CCCP

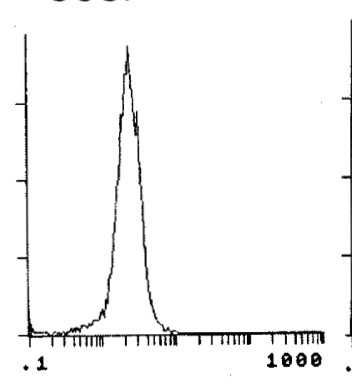

BH3BAD

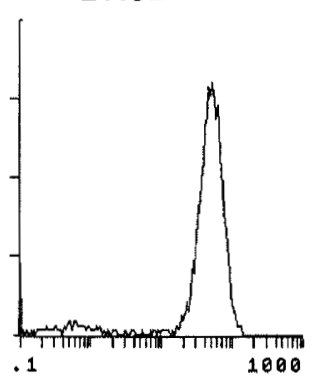

ANT

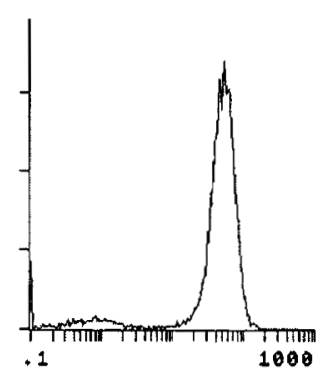

ANTBH3BAD

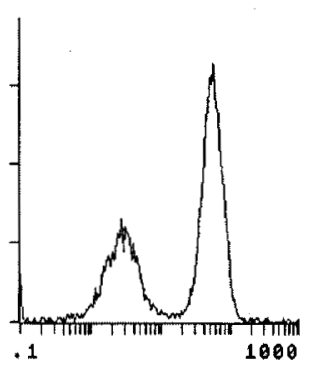

\section{$\Delta \Psi_{\mathrm{M}}$}

Figure 9 ANTBH3BAD induces loss of $\Delta \Psi \mathrm{C}_{\mathrm{M}}$. 32D cells $\left(5 \times 10^{5}\right.$ cells $)$ were treated with BH3BAD, ANT, ANTBH3BAD, at a final concentration of $50 \mu \mathrm{M}$. Cells were also treated with the uncoupling agent carbonyl cyanide m-chlorophenylhydrazone (CCCP) (final concentration $100 \mu \mathrm{M}$ ) to induce complete loss of $\Delta \Psi \mathrm{C}_{\mathrm{M}}$ and thereby serve as a positive control. $\Delta \Psi \mathrm{C}_{\mathrm{M}}$ was detected by staining with DilC1 $(40 \mathrm{~nm})$. Changes in $\Delta \Psi \mathrm{C}_{\mathrm{M}}$ were measured at various times after theaddition of the peptides by flow cytometry. A representative time course for the change in $\Delta \Psi \mathrm{C}_{\mathrm{M}}$ is shown $(\mathbf{A})$. A representative flow cytometric experiment after the addition of the peptides is presented $(\mathbf{B})$

cytoplasm. The plasma membrane was permeablized with digitonin and mitochondrial activity was driven with succinate. BH3BAD $(50 \mu \mathrm{M})$ was added to the permeablized cells for $15 \mathrm{~min}$ and changes in $\Delta \Psi_{\mathrm{M}}$ were measured by flow cytometry. BH3BAD induced a $4.6 \pm 0.3$-fold loss of $\Delta \Psi_{\mathrm{M}}$ compared to treatment with digitonin and succinate alone. Therefore, when internalized into cells and exposed to the mitochondria, BH3BAD displays an ability to induce loss of $\Delta \Psi_{\mathrm{M}}$ like the fusion peptide.

\section{ANTBH3BAD induces caspase-3 activation, but caspase inhibitors do not protect against cell death}

Mitochondrial damage can activate caspases. To determine if the cytotoxicity of ANTBH3BAD is caspasedependent, we studied the effect of ANTBH3BAD on caspase activation. Treatment with ANTBH3BAD induced a $5 \pm 0.9$-fold increase in caspase- 3 activity compared to untreated cells. In contrast, no increase in caspase-3 activity was seen after treatment with ANT or BH3BAD. Next, we investigated the effects of the general caspase inhibitor zVAD on ANTBH3BAD-induced caspase activation and cytotoxicity. Pretreatment with $100 \mu \mathrm{M}$ zVAD for $1 \mathrm{~h}$ prevented ANTBH3BAD-induced caspase-3 activation. Pretreatment with $z V A D$ also prevented the death of $32 \mathrm{D}$ cells after withdrawal of $\mathrm{IL}-3$ indicating that $\mathrm{ZVAD}$ is capable of inhibiting apoptotic stimuli in this cell line. Interestingly, pretreatment with zVAD did not inhibit ANTBH3BAD-induced cell death (Figure 10). Therefore, ANTBH3BAD induces caspase-dependent cell death, but in the presence of caspase inhibitors, it remains cytotoxic due to caspase-independent mechanisms.

\section{P-glycoprotein protects against ANTBH3BAD toxicity}

Over-expression of p-glycoprotein is another important mechanism of multidrug resistance and is a poor prognostic marker in patients with leukemia. ${ }^{20,21}$ Peptides and proteins can act as substrates of p-glycoprotein. ${ }^{22-24}$ Therefore, we studied the effects of p-glycoprotein overexpression on the toxicity of our peptides. CEM cells and CEM VBL cells over-expressing p-glycoprotein were treated with varying concentrations of ANTBH3BAD. Compared to the CEM parent cell line, CEM VBL cells displayed resistance to ANTBH3BAD that was most apparent at a final concentration of $10 \mu \mathrm{M}$ ANTBH3BAD. Pretreatment of CEM VBL with the p-glycoprotein inhibitor cyclosporine (final concentration $10 \mu \mathrm{M}$ ) for one hour restored the toxicity of ANTBH3BAD to levels seen in the wild type CEM line (Figure 11). Therefore, p-glycoprotein limits the toxicity of this peptide, but the effect can be reversed with p-glycoprotein inhibitors. 


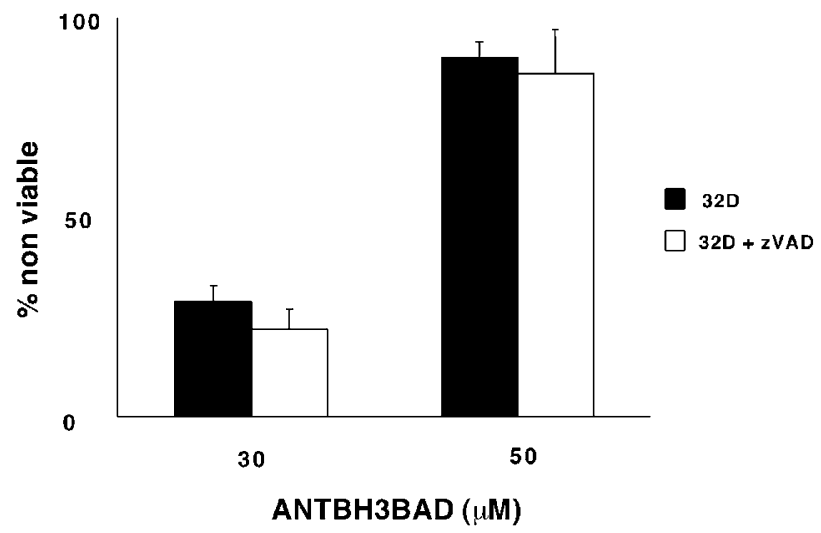

Figure 10 zVAD fails to prevent cell death. $32 \mathrm{D}$ cells $\left(5 \times 10^{5}\right.$ cells) were pretreated with $100 \mu \mathrm{M} z \mathrm{VAD}$ for $1 \mathrm{~h}$ followed by the addition of ANTBH3BAD (30 and $50 \mu \mathrm{M})$. After $3 \mathrm{~h}$, cell viability was determined by trypan blue extrusion. The results represent the mean of three experiments
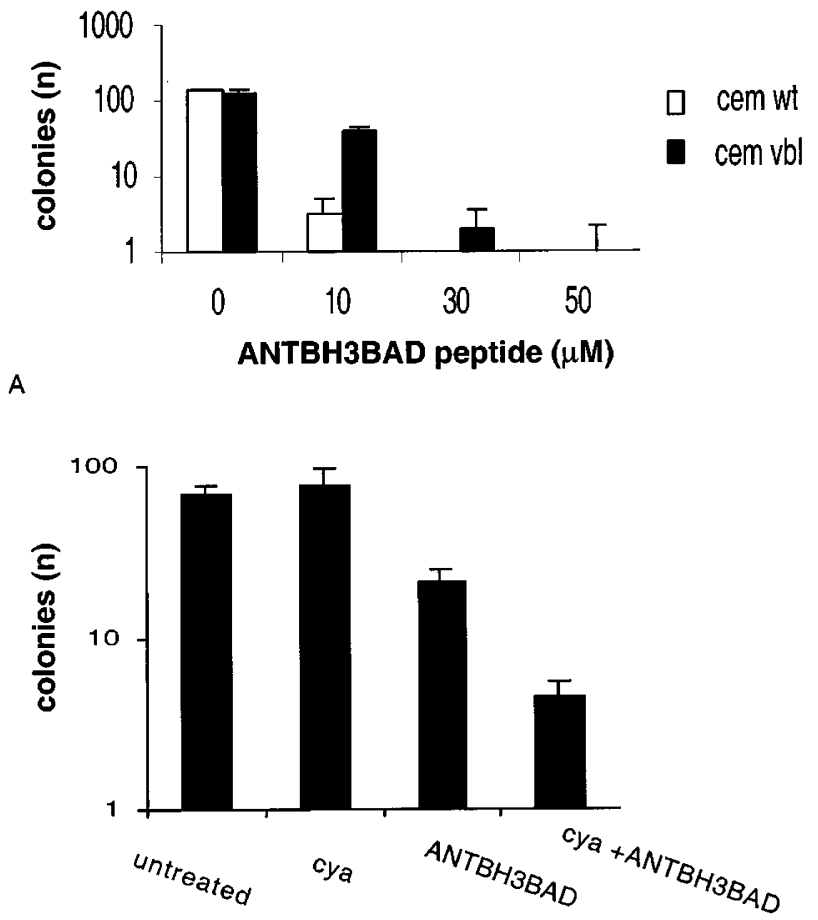

treatment

B

(cya 10uM, ANTBH3BAD 10 $\mu$ M)

Figure 11 p-glyocprotein protects against ANTBH3BAD toxicity. (A) CEM and the $p$-glycoprotein over-expressing cell line CEM VBL were treated with ANT, BH3BAD, or ANTBH3BAD for $3 \mathrm{~h}$ at various concentrations. Cells were then seeded in complete medium with $0.85 \%$ methylcellulose. One week after seeding the number of colonies formed was counted. (B) CEM VBL cells were pretreated with cyclosporine (cya) at a final concentration of $10 \mu \mathrm{M}$ for $1 \mathrm{~h}$. ANTBH3BAD was added at a final concentration of $10 \mu \mathrm{M}$. Three hours after incubation, the cells were seeded in complete medium with $0.85 \%$ methylcellulose. One week after seeding the number of colonies formed was counted

\section{Discussion}

As a prototype for a novel therapeutic agent, we studied the effects of the BH3 domain of human BAD fused to the ANT internalization sequence. This fusion peptide induced a rapid cell death in all cells tested including yeast. We demonstrated that this peptide was toxic because of its alpha helical shape and that it acted by disrupting mitochondrial function.

In a cell free system, the ANTBH3BAD peptide bound $\mathrm{Bcl}-2$ with higher affinity than the BH3BAD peptide alone. A similar finding was reported with BH3BAD fused to the fatty acid moiety $\mathrm{cpm}^{8}{ }^{8}$ The increased binding likely reflects the additional interaction of the positively charged ANT sequence with $\mathrm{Bcl}-2$.

Despite being capable of binding $\mathrm{Bcl}-2$, the cytotoxicity of ANTBH3BAD was independent of the Bcl-2 pathway. Cells over-expressing Bcl-2 showed no resistance to the peptide and a mutant fusion peptide unable to bind $\mathrm{Bcl}-2$ was as toxic as the wild-type. We could not demonstrate $\mathrm{Bcl}-2$-dependence because the alpha helical properties of the peptide overcame the protective role of $\mathrm{Bcl}-2$.

The cytotoxicity of ANTBH3BAD was not an artifact of the fusion peptide, but rather related to the helical properties of BH3BAD. As evidence to this point, BH3BAD was capable of inducing loss of $\Delta \Psi_{M}$ in permeabilized cells.

Previous studies of full length $B A D^{25,26}$ or the $B H 3$ domain of $B A D^{6-8}$ have not reported toxicity attributable to the alpha helical configuration. These studies demonstrated that over-expression of $\mathrm{Bcl}-2$ and $\mathrm{Bcl}-\mathrm{xL}$ inhibits apoptosis induced by the full-length protein and peptide. Furthermore, mutants that do not bind $\mathrm{Bcl}-2$ are not toxic. ${ }^{6-8,25,26} \mathrm{~A}$ number of explanations may account for our ability to detect toxicity due to the alpha helicity of BH3BAD. First, fusing the $B H 3$ domain of BAD to the ANT internalization sequence may have targeted the peptide more effectively to the mitochondria where its alpha helical shape could disrupt the inner membrane. BH3BAD peptides coupled to the cpm fatty acid moiety were confined to the cytoplasm. In contrast, our peptide was distributed diffusely throughout the cell. Second, the concentration of BAD used in the previous studies may have been too low to detect the effects of the alpha helix. If BH3 BAD-mutants unable to bind $\mathrm{Bcl}-2$ or $\mathrm{Bcl}-\mathrm{xL}$ were used at higher concentrations, the cytotoxicity from the alpha helical shape might have become apparent. Finally, the full-length protein BAD may constrain the death promoting attributes of the alpha helical $\mathrm{BH} 3$ domain.

In a previous report by Ellerby et al., ${ }^{12}$ the 14 amino acid alpha helix (KLALAK) $)_{2}$ induced cell death and apoptosis. The peptide induced mitochondrial swelling and caspase-3 activation in isolated mitochondria but the effect on $\Delta \Psi_{\mathrm{M}}$ was not reported. In addition, the effects of $\mathrm{Bcl}-2$ and $\mathrm{p}$ glycoprotein on the toxicity of (KLALAK) 2 were not studied. Here, we have demonstrated that ANTBH3BAD disrupts mitochondria and induces loss of $\Delta \Psi_{\mathrm{M}}$ in intact and permeablized cells. Unlike the (KLALAK $)_{2}$ peptide, the toxicity of ANTBH3BAD was not inhibited by the general caspase inhibitor zVAD. zVAD can inhibit mitochondrial induced caspase activation, but it does not prevent the 
peptide from damaging the mitochondria. As mitochondrial damage continues, the ability of the mitochondria to synthesize ATP is lost, and, as a consequence, cells undergoes a metabolic and caspase independent death. ${ }^{27-29}$

The finding of toxicity not affected by $\mathrm{Bcl}-2$ suggests that alpha helical molecules such as ANTBH3BAD can be potent anti-cancer agents capable of overcoming important mechanisms of multidrug resistance. To see if other mechanisms of multidrug resistance impact the toxicity of the peptide, we studied the effects of p-glycoprotein. Overexpression of $p$-glycoprotein protected against the toxicity of ANTBH3BAD and this protection was reversed by adding the p-glycoprotein inhibitor cyclosporine. P-glycoprotein is best known for its role in extruding chemotherapeutic agents, but it also exports peptides and large proteins such as IL-2 and gamma interferon. $^{22-24,30,31}$ Therefore, $p$-glycoprotein may protect the cells from the toxicity of ANTBH3BAD by exporting it out of the cells. Alternatively, it may be abrogating the peptide's toxicity through its role in inhibiting apoptosis. p-glycoprotein inhibits apoptosis in response to Fas ligand, ultraviolet irradiation, and serum starvation, and the addition of verapamil can restore the apoptotic signals of these stimuli. $^{32,33}$ Currently, it is unknown how it directly protects cells from these apoptotic stimuli.

In conclusion, we describe a cytotoxic effect of the $\mathrm{BH} 3$ domain of BAD due to its alpha helical properties and have harnessed this cytotoxic action by fusing BH3BAD to the ANT sequence. This fusion creates a cytotoxic peptide that overcomes two major forms of drug resistance-Bcl-2 and caspase inhibitors. As such, this compound may have clinical utility if it can be selectively targeted. This work also furthers the understanding of how alpha helical peptides induce apoptosis in mammalian cells and investigates factors that impact their toxicity.

\section{Materials and Methods}

\section{Peptides}

Peptides (Table 1) were synthesized commercially to our specifications (Amgen, Colorado) and were purified to greater than $95 \%$ purity by reverse phase HPLC. Peptides were resuspended in DMSO and stored at $-20^{\circ} \mathrm{C}$.

\section{Real time surface plasmon resonance}

Binding of $\mathrm{Bcl}-2$ to the peptides was assessed using a BIAcore sensor system(BIAcore, Uppsala, Sweden). ANTBH3BAD, ANT, BH3BAD, the L114A D119R mutant peptide, and BSA were diluted in $10 \mathrm{mM} \mathrm{Na}$ acetate $\mathrm{pH} 5$ and coupled to a CM5 sensor surface activated with
$37.5 \mathrm{mg} / \mathrm{ml} \mathrm{N}$-Ethyl- $\mathrm{N}^{\prime}$-(3'dimethylaminopropyl) carbodiimide hydrochloride (EDC) and $7.5 \mathrm{mg} / \mathrm{ml} \mathrm{N}$-hydroxysuccinimide (NHS). Peptides were added to saturate the chip. Remaining reactive groups on the chip were then inactivated with $1 \mathrm{M}$ ethanolamine $\mathrm{pH}$ 8.5. GST-Bcl-2 (Santa Cruz) was diluted in running buffer (0.01 M HEPES pH 7.4, $0.15 \mathrm{NaCl}, 3 \mathrm{mM}$ EDTA, and $0.005 \%$ polysorbate $20(\mathrm{v} / \mathrm{v}))$ and injected onto the sensor chip at varying concentrations. All experiments were performed at $25^{\circ} \mathrm{C}$. Between injections of GST-BCL-2, the chip was washed with running buffer and regenerated with $1 \mathrm{M} \mathrm{NaCl}$ and $50 \mathrm{mM}$ $\mathrm{NaOH}$. Data were analyzed with the BIAevaluation software.

\section{Cell lines}

HeLa cells were grown in Dulbeco's Modified Eagle Medium with high glucose (DMEM H21). CEM and the vinblastine resistant CEM cell line over-expressing p-glyocoprotein (CEM VBL) were grown in RPMI 1640. A 32D cell line over-expressing Bcl-2 (a gift from S Berger) was created by infecting $32 \mathrm{D}$ cells with a retrovirus containing murine $\mathrm{Bcl}-$ 2. Over-expression of Bcl-2 was confirmed by Western blot. 32D cells were maintained in RPMI 1640 and $2 \%$ WeHi-3B conditioned medium as a source of IL-3. All cell lines were supplemented with $10 \%$ fetal calf serum, penicillin and streptomycin. Cells were grown at $37^{\circ} \mathrm{C}$ with $5 \%$ $\mathrm{CO}_{2}$ in a humid atmosphere.

\section{Internalization of the peptides}

Biotinylated ANT or ANTBH3BAD peptides were added to $1 \times 10^{6} 32 \mathrm{D}$ cells at a final concentration of $50 \mu \mathrm{M}$ in serum free DMEM H21 (SFDMEM). After $20 \mathrm{~min}$, the cells were washed twice in PBS and fixed in $4 \%$ paraformaldehyde in PBS ( $\mathrm{pH} \mathrm{7.0)}$ for $10 \mathrm{~min}$ at room temperature. After fixation, cells were washed in PBS and permeabilized with $1 \%$ Triton X-100 in PBS for 10 min at room temperature. Cells were again washed in PBS and incubated with $3 \%$ bovine serum albumin in PBS for $1 \mathrm{~h}$. Streptavidin-FITC (5 $\mu$ l) (Pierce) in $3 \%$ bovine serum albumin in PBS was added to the cells in a total volume of $500 \mu$ land incubated at room temperature for $30 \mathrm{~min}$. Cells were washed in PBS and analyzed by flow cytometry (FACScan; Becton Dickinson, Immunocytometry system, CA, USA) or mounted on glass slides and viewed with a fluorescent (Leica DMLB) or a confocal fluorescent (Zeiss LSM 510) microscope.

\section{Clonogenic colony assay}

Suspension cells $\left(5 \times 10^{4}\right)$ in SF-DMEM H21 were treated with the peptides for $3 \mathrm{~h}$. Equal volumes of cells were plated in quadruplicate into 96 -well plates in complete medium, with $0.85 \%$ methylcellulose. One week after seeding, the number of colonies formed were counted. HeLa cells $\left(2 \times 10^{5}\right)$ in DMEM H21 with $10 \%$ FCS were seeded into 6 well plates. Twenty-four hours later, they were treated with the peptides for $3 \mathrm{~h}$ in SF-DMEM H21. Following treatment with the peptides, equal volumes of cells were plated in triplicate into $100 \mathrm{~mm}^{3}$ tissue culture plates. One week after seeding, the medium was removed, the plates stained with methylene blue, and the number of

Table 1 Peptides

\begin{tabular}{lcc}
\hline Peptide & Internalization sequence & BH3 BAD sequence \\
\hline ANT & RQIKIWFQNRRMKWKK & NLWAAQRYGRELRRMSDEFVD \\
BH3 BAD & & NLWAAQRYGRELRRMSDEFVD \\
ANTBH3BAD & RQIKIWFQNRRMKWKK & NLWAAQRYGREARRMSREFVD \\
ANTBH3BAD-L114A D119R & RQIKIWFQNRRMKWKK & NLWPPQRYGREPRRMSDEFVD \\
ANTBH3BAD Non-helix mutant & RQIKIWFQNRRMKWKK & \\
\hline
\end{tabular}


colonies formed were counted. Yeast strain $S$. cerevisiae was grown overnight in YPD broth at $30^{\circ} \mathrm{C}$. The next morning, $3 \mathrm{ml}$ of culture was added to $7 \mathrm{ml} \mathrm{YPD}$ broth and grown at $30^{\circ} \mathrm{C}$ to an OD 595 of $0.3-0.35$. One $\mathrm{ml}$ of culture was diluted in PBS. Peptides were added and incubated with the yeast for $2 \mathrm{~h}$ at room temperature. Equal volumes of cells were plated in triplicate onto YPD plates and incubated at $30^{\circ} \mathrm{C}$. Four days later, the number of colonies formed were counted.

\section{Annexin V assay}

Peptides were added to $1 \times 10^{6} 32 \mathrm{D}$ cells in SF-DMEM at a final concentration of $50 \mu \mathrm{M}$ for $30 \mathrm{~min}$. FITC conjugated Annexin V $(5 \mu \mathrm{l})$ (Pharmingen) and propidium iodide (PI) (Sigma) (final concentration $5 \mu \mathrm{g} / \mathrm{ml}$ ) were added. The cells were incubated for $20 \mathrm{~min}$ at room temperature in the dark and fluorescence was measured by flow cytometry (FACScan; Becton, Dickinson, Immunocytometry system, CA, USA). The Lysis II program was used to analyze these data. Cells staining positive for Annexin $\mathrm{V}$ and negative for $\mathrm{PI}$ were deemed apoptotic.

\section{Circular dichroism}

ANT and ANTBH3BAD peptides were dissolved in $0.1 \mathrm{M} \mathrm{Na}_{2} \mathrm{HPO}_{4}$ buffer, $0.1 \mathrm{MNa}_{2} \mathrm{HPO}_{4}$ bufferand $1 \%$ SDS or $0.1 \mathrm{M} \mathrm{Na}_{2} \mathrm{HPO}_{4}$ bufferand $40 \%(\mathrm{v} / \mathrm{v})$ TFE at approximately $1 \mathrm{mg} / \mathrm{ml}$. Concentrations of the peptides were determined by tryptophan absorbance. ${ }^{30}$ Peptides were aliquoted into a $1 \mathrm{~cm}$ path length cuvette. CD spectra were recorded at room temperature on an AVIV CD spectrometer model 62A DS. Spectra were collected with an averaging time of $10 \mathrm{~s}$ per point. Each point represents the averaged ellipticity value recorded over a $1 \mathrm{~nm}$ spectral interval.

\section{Measurement of mitochondrial membrane potential, reactive oxygen intermediates and cytosolic calcium}

Changes in mitochondrial membrane potential $\left(\Delta \Psi_{\mathrm{M}}\right)$ were detected by staining the cells with DilC1(5) $\left(1,1^{\prime} 3,3,3^{\prime}, 3^{\prime}\right.$-hexamethylindodicarbocyanine) at a final concentration of $40 \mathrm{nM}$ and propidium iodide (final concentration $5 \mu \mathrm{g} / \mathrm{ml}$ ) as described previously. ${ }^{31-33}$ Cells stained with DilC1(5) were incubated at $37^{\circ} \mathrm{C}$ for $20 \mathrm{~min}$ and then analyzed by flow cytometry (Coulter Epics Elite, Coulter, FL, USA) by exciting at $633 \mathrm{~nm}$ and measuring through a $675 \pm 20 \mathrm{~nm}$ bandpass filter. While measuring changes in $\Delta \Psi_{\mathrm{M}}$ over time, stained cells were maintained at $37^{\circ} \mathrm{C}$.

Changes reactive oxygen intermediate production, and cytosolic calcium were detected by staining the cells with $5 \mu \mathrm{M}$ carboxy-DCFDA (carboxy-dichlorofluroescin diacetate), and $3 \mu \mathrm{M}$ indo-1 AM, respectively. Carboxy-DCF excitation was at $488 \mathrm{~nm}$ and fluorescence was measured using a $525 \pm 10 \mathrm{~nm}$ bandpass filter. Ionized calcium was obtained by electronic ratio measurement of indo- 1 AM emission at 405 and $525 \mathrm{~nm}$ at an excitation of $360 \mathrm{~nm}$.

To assess changes in $\Delta \Psi_{\mathrm{M}}$ in the presence of a permeabilized cell membrane, 32D cells were treated according to the method of Pham et al. ${ }^{31}$ Briefly, cells were suspended in respiratory buffer $(0.25 \mathrm{M}$ sucrose, $2 \mathrm{mM} \mathrm{KH}_{2} \mathrm{PO}_{4}, 5 \mathrm{mM} \mathrm{MgCl}$, $1 \mathrm{mM}$ EDTA, $0.1 \%$ fatty acid free BSA, $1 \mathrm{mM} \mathrm{ADP}$, and $20 \mathrm{mM}$ MOPS (pH 7.4)). Digitonin $(4 \mu \mathrm{g} / \mathrm{ml}$ final concentration) was added to the cells for $5 \mathrm{~min}$. Successful permeabilization was documented by detecting entry of propidium iodine into the cells. Mitochondrial function was driven by adding $5 \mathrm{mM}$ succinate, a complex II substrate. BH3BAD peptides were added at a final concentration of $50 \mu \mathrm{M}$ and cells were incubated at $37^{\circ} \mathrm{C}$ for $15 \mathrm{~min} . \Delta \Psi_{\mathrm{M}}$ was then measured by flow cytometric analysis after staining with $40 \mathrm{nM}$ DilC1(5).

\section{Caspase-3 activation}

Caspase-3 activation was measured with the Apo-Alert Caspase-3 Fluorescent assay kit (Clontech, CA, USA) according to the manufacturers instructions. Cells $\left(1 \times 10^{6}\right)$ were treated with the peptides $(50 \mu \mathrm{M})$ for $2 \mathrm{~h}$ and lysed. The caspase-3 substrate DEVD$\mathrm{AMC}$ was added to the lysate and incubated for $1 \mathrm{~h}$ at $37^{\circ} \mathrm{C}$. Release of free AMC was measured in a fluorometer (Photon Techonology International) with a $400 \mathrm{~nm}$ excitation filter and a $505 \mathrm{~nm}$ emission filter.

\section{Acknowledgements}

We would like to thank R Lutz and E Hollinger (Immunogen, MA, USA) for their helpful advice and discussion. AD Schimmer was supported by fellowships from the Canadian Institute of Health Research and the Leukemia Research Fund of Canada. MR Trus was supported by a fellowship from the Leukemia Research Fund of Canada

\section{References}

1. Pepper C, Bentley P and Hoy T (1996) Regulation of clinical chemoresistance by bcl-2 and bax oncoproteins in B-cell chronic lymphocytic leukaemia. Br. J. Haematol. 95: 513-517

2. Sangflet $O$, Osterborg A, Grander D, Anderbring E, Ost A, Mellstedt $H$ and Einhorn S (1995) Response to interferon therapy in patients with multiple myeloma correlates with expression of Bcl-2 oncoprotein. Int. J. Cancer 63: $190-192$

3. Kitada S, Takayama S, De Riel K, Tanaka S and Reed JC (1994) Reversal of chemoresistance of lymphoma cells by antisense-mediated reduction of bcl-2 gene expression. Antisense Res. Dev. 4: 71-79

4. Piche A, Grim J, Rancourt C, Gomez-Navarro J, Reed JC and Curiel DT (1998) Modulation of $\mathrm{Bcl}-2$ protein levels by intracellular anti-Bcl-2 single-chain antibody increases drug-induced cytotoxicity in the breast cancer cell line MCF7. Cancer Res. 58: $2134-2140$

5. Miyashita T and Reed JC (1993) Bcl-2 oncoprotein blocks chemotherapyinduced apoptosis in a human leukemia cell line. Blood 91: 151-157

6. Kelekar A, Chang B, Harlan J, Fesik SW and Thompson CB (1997) Bad is a BH3 domain-containing protein that forms an inactivating dimer with $\mathrm{Bcl}-\mathrm{xL}$. Mol. Cell. Biol. 17: 7040-7046

7. Zha J, Harada H, Konstantin O, Jockel J, Waksman G and Korsmeyer S (1997) $\mathrm{BH} 3$ domain of $\mathrm{BAD}$ is required for heterodimerization with $\mathrm{Bcl}-\mathrm{xL}$ and proapoptotic activity. J. Biol. Chem. 272: 24101-24104

8. Wang JL, Zhang ZJ, Choksi S, Shan S, Lu X, Croce CM, Alnermri ES, Korngold R and Huang Z (2000) Cell permeable Bcl-2 binding peptides: a chemical approach to apoptosis induction in tumor cells. Cancer Res. 60: 1498-1502

9. Blondelle SE and Houghten RA (1992) Design of model amphipathic peptides having potent antimicrobial action. Biochemistry 31: 12688-12694

10. Bessale R, Kapitkovsky A, Gorea A, Shalit I and Fridkin M (1990) All-D-magainin: chirality, antimicrobial activity and proteolytic resistance. FEBS Lett. 274: 151 155

11. Saleh MT, Ferguson J, Boggs JM and Gariepy J (1996) Insertion and orientation of a synthetic peptide representing the $C$-terminus of the $A 1$ domain of Shiga toxin into phospholipid membranes. Biochemistry 35: 9325-9334

12. Ellerby HM, Arap W, Ellerby LM, Kain R, Andrusiak R, Del Rio G, Krajewski S, Lombardo CR, Rao R, Ruoslahti E, Bredesen DE and Pasqualini R (1999) Anticancer activity of targeted pro-apoptotic peptide. Nat. Med. 5: 1032-1038

13. Derossi D, Calvet S, Trembleau A, Brunissen A, Chassaing G and Prochiantz A (1996) Cell internalization of the third helix of the Antennapedia homeodomain is receptor-independent. J. Biol. Chem. 271: 18188-18193

14. Derossi D, Jolio A, Chassaing G and Prochiantz A (1994) The third helix of the Antennapedia homeodomain translocates through biological membranes. J. Biol. Chem. 269: 10444-10450

15. Fenton M, Bone N and Sinclair A (1998) The efficient and rapid import of a peptide into primary B and T lymphocytes and a lymphoblastoid cell line. J. Immunol. Methods 212: $41-48$ 
16. Goasguen JE, Dossot JM, Fardel O, LeMee F, Le Gall E, Leblay R, LePrise PY, Chaperson J and Fauchet R (1993) Expression of the multidrug resistanceassociated P-glycoprotein (P-170) in 59 cases of de novo acute lymphoblastic leukemia: prognostic implications. Blood 81: 2394-2398

17. Campos L, Guyotat D, Archimbaud E, Calmard-Oriol P, Tsuruso T, Troncy J, Treille D and Fiere D (1992) Clinical significance of multidrug resistance Pglycoprotein expression on acute nonlymphoblastic leukemia cells at diagnosis. Blood 79: 473-476

18. Drach J, Gsur A, Hamilton G, Zhao S, Angerler J, Fiegl M, Zojer N, Raderer M, Haberl I, Andreeff M and Huber H (1996) Involvement of P-glycoprotein in the transmembrane transport of interleukin-2 (IL-2), II-4, and interferon-gamma in normal human T lymphocytes. Blood 88: 1747-1754

19. Sharom FJ, Lu P, Liu R and YuX (1998) Linear and cyclic peptides as substrates and modulators of P-glycoprotein: peptide binding and effects on drug transport and accumulation. Biochem. J. 333: 621-630

20. Sharom FJ, DiDiodato G, Yu X and Ashbourne KJD (1995) Interaction of the Pglycoprotein multidrug transporter with peptides and ionophores. J. Biol. Chem. 270: $10334-10341$

21. Yang E, Zha J, Jockel J, Boise LH, Thompson CB and Korsmeyer S (1995) Bad, a heterodimeric partner for $\mathrm{Bcl}-\mathrm{xL}$ and $\mathrm{Bcl}-2$ displaces Bax and promotes cell death. Cell 80: 285-291

22. Zha J, Harada H, Yang E, Jockel J and Korsmeyer S (1996) Serine phosphorylation of death agonist $B A D$ in response to survival factor results in binding to 14-3-3 not Bcl-xL. Cell 87: 619-628

23. Qian T, Herman B and Lemasters JJ (1999) The mitochondrial permeability transition mediates both necrotic and apoptotic death of hepatocytes exposed to Br-A23187. Toxicol. Appl. Pharmacol. 154: 117-125

24. Lemasters JJ, Nieminen AL, Qian T, Trost LC, Elmore SP, Nishimura Y, Crowe RA, Casciao W, Bradham CA, Brenner DA and Herman B (1998) The mitochondrial permeability transition in cell death; a common mechanism in necrosis, apoptosis and autophagy. Biochim. Biophys. Acta. 1366: 177-196
25. Eguchi Y, Shimizu S and Tsujimoto Y (1997) Intracellular ATP levels determine cell death fate by apoptosis or necrosis. Cancer Res. 57: 1835-1840

26. Sarkadi B, Muller M, Homolya L, Hollo Z, Seprodi J, Germann UA, Gottesman MM, Price EM and Boucher RC (1994) Interaction of bioactive hydrophobic peptides with the human multidrug transporter. FASEB J. 8: 766-770

27. Sharom FJ, Yu X, DiDonato G and Chu JWK (1996) Synthetic hydrophobic peptides are substrates for P-glycoprotein and stimulate drug transport. Biochem. J. 320: $421-428$

28. Robinson LJ, Roberts WK, Ling TT, Lamming D, Sternberg SS and Roepe PD (1997) Human MDR1 protein overexpression delays the apoptotic cascade in Hinese hamster ovary fibroblasts. Biochemistry 36: 11169-11178

29. Johnstone RW, Cretney E and Smyth MJ (1999) P-glycoprotein protects leukemic cells against caspase-dependent, but not caspase-independent cell death. Blood 93: 1075-1085

30. Edelhoch H (1967) Spectroscopic determination of tryptophan and tyrosine in proteins. Biochemistry 6: $1948-1954$

31. Pham N, Robinson BH and Hedley DW (2000) Simultaneous detection of mitochondrial respiratory chain activity and reactive oxygen in digitonin permeabilized cells using flow cytometry. Cytometry 41: 245-251

32. Sheng-Tanner X, Bump EA and Hedley DW (1998) An oxidative stress mediated death pathway in irradiated human leukemia cells mapped using multilaser flow cytometry. Radiation Res. 150: 636-647

33. Hakem R, Hakem A, Duncan GS, Henderson JT, Woo M, Soenga MS, Eli A, Luis Pompa J, Kagi D, Khoo W, Potter J, Yoshida R, Kaufman SA, Lowe SW, Penninger JM and Mak TW (1998) Differential requirement for caspase-9 in apoptotic pathways in vivo. Cell 94: $339-352$ 